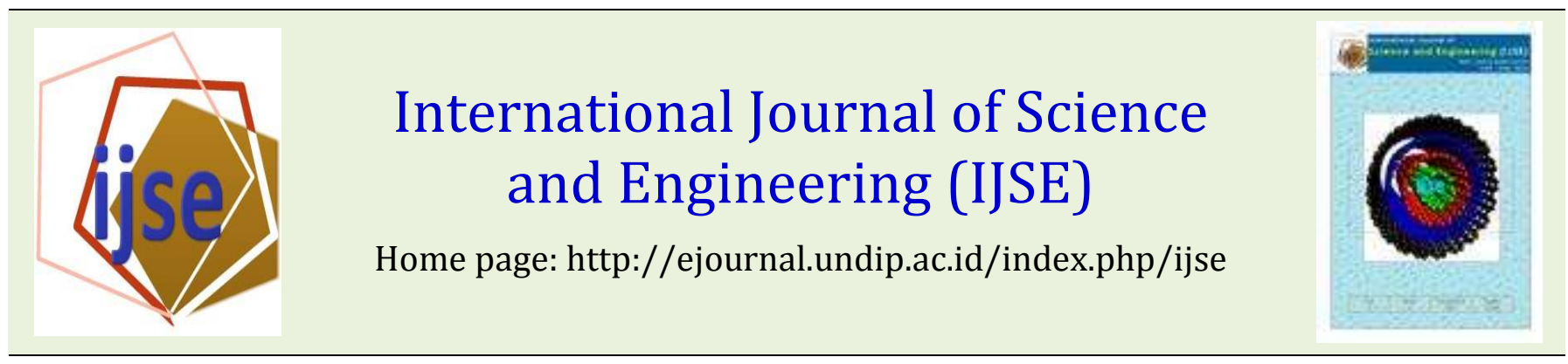

\title{
Comparison of Physicochemical Properties of Bunch Press Fibre Cellulose and Cyclone Fibre Cellulose of Waste From Industry Crude Palm Oil (CPO)
}

\author{
Irfan Gustian, Eka Angasa, Ghufira, Miliani, Hairulumah \\ Universitas Bengkulu, Department of Chemistry-Faculty of Mathematics and Natural Sciences, \\ 38371 JI, Raya Kandang Limun-Bengkulu, Indonesia \\ Coorresponding Author: unibfan@yahoo.com
}

\begin{abstract}
Study on comparison the physicochemical properties of bunch press fibre cellulose (Bpfc) and cyclone fibre cellulose (Cfc) wastes from industry Crude Palm oil (CPO) have been performed. The physicochemical properties both of celluloses have been done such as the average degree of polymerization (DP), solubility properties, functional group analysis, thermal properties and X-ray diffraction patterns. The average degrees of polymerization (DP) have been obtained 2195 and 567 for Bpfc and Cfc. Bunch press fibre cellulose and cyclone fibre cellulose were soluble in cupriethylenediamine (CED). FT-IR analysis showed the same pattern of spectrum but different intensities. Thermal stability of bunch press fibre cellulose and cyclone fibre cellulose remains stable up to a temperature of $250{ }^{\circ} \mathrm{C}$. Glass transition bunch press fibre cellulose greater than the glass transition cyclone fibre cellulose and X-ray diffraction pattern shows the same pattern and intensity varies.
\end{abstract}

Keywords - Bunch press fibre cellulose, cyclone fibre cellulose, physicochemical properties, waste industry Crude Palm oil.

Submission: 17 November 2013

Corrected :18 December 2013

Accepted: 23 December 2013

Doi: $10.12777 /$ ijse.6.1.47-51

[How to cite this article: Gustian. I., Angasa. E., Ghufira, Miliani, Hairulumah, 2014. Comparison the physicochemical properties of bunch press fibre cellulose and cyclone fibre cellulose of waste from industry Crude Palm Oil (CPO). International Journal of Science and Engineering, 6(1)-47-51, Doi: $\underline{10.12777 / \text { ijse.6.1.47-51] }}$

\section{INTRODUCTION}

Green products and environmental friendly are those that use less environmental resources, emit less pollutant to the different environmental media, use a substitute for genuine resources, utilize waste in the production of material and save energy used for industrial processes. Cellulose for industrial purposes is usually obtained from wood plant resources using different pulping purposes. Resources recovery is new trend to achieve sustainable development. Wastes are considered secondary material resources and the same time are renewable material recources [1]. In the search for alternative applications of biomass, the concept of biorefinery and production of cellulose microfibrillated from native cellulose have the subject of intensive investigation nowdays.

Cellulose, the major component of higher plant biomass, is the most abundant biopolymer in nature and is therefore attractive as a sustainable source of materials for industrial processes [2]. In particular, its use as a raw material for the production of pulp and paper makes it commercially important. Additionally, the use of cellulose and its derivatives in a diverse array of other applications, such as films, plastics, coatings, suspension agents, and composites, continues to grow on a worldwide basis [3].

Palm oil plantations in Indonesia currently occupies a vast area, which has grown in 21 provinces. The largest area in Sumatra, followed by Borneo, Celebes and Papua. Five provinces widest row is Riau (1.3 million ha), North Sumatra (964.3 thousand hectares), South Sumatra (532.4 thousand hectares), West Kalimantan (466.9 thousand hectares) and Jambi (466.7 thousand hectares). The fifth province has 3770 million ha or $67.4 \%$ of the 5597 million ha in Indonesia. In Bengkulu Province have an area of 83583 ha of palm oil plantations. While the installed capacity of production for palm oil millers to Bengkulu province there are 12 units of the plant with a production capacity of 546 ton of fresh fruit bunches (FFB) per hour. 
For PT. Palm Oil Plantation Bio-Nusantara Indoneisa Bengkulu currently production capacity of 45 tonnes of fresh fruit bunches per hour. Production of 1 ton of fresh fruit bunches per hour will produce about $190 \mathrm{~kg}$ of waste fibre shell/cyclone fibre cellulose and $230 \mathrm{~kg}$ of fibre obtained from palm empty fruit bunches/bunch press fibre cellulose [4].

So far the PT. Bio Nusantara beneficiaries has been used as a raw material for animal feed. In addition, fibre is only used as a boiler fuel in palm oil processing industry, and there is also a natural fertilizer for oil palm plantations. This fibre is still very abundant although some have been used. Sufficiently number of waste fibre is very supportive to undertake diversification utilization. It is known that the fibre contains cellulose which is the main component, although there are minor components such as lignin, fats, waxes, terpenes, terpenoids, steroid, phenolic compounds, protein and starch. All of this components can be removed by solvent method and soaking when the pulping process. These materials provide a low-cost feedstock for biological production of fuels and chemicals, which offer economic, environmental, and strategic advantages [5]. Its use as a raw material for the production of pulp and paper makes it commercially important. Additionally, the use of cellulose and its derivatives in a diverse array of other applications, such as films, plastics, coatings, suspension agents, and composites, continues to grow on a worldwide basis. Previous studied about physicochemical properties of cellulose waste from palm oil industry has not reported.

In this paper we presented the results of examination of the degree of polymerization, solubility properties, functional group analysis, thermal properties, X-ray diffraction patterns of bunch press fibre cellulose and cyclone fibre cellulose.

\section{EXPERIMENTAL}

\subsection{Materials and Preparation}

Bunch press fibre cellulose (Bpfc) and cyclone fibre cellulose (Cfc) wastes from crude palm oil industry (CPO) (Figure 1, from PT. Palm Oil Plantation Bio-Nusantara Indoneisa, Bengkulu), cupriethylenediamine (CED; Merck, Darmstadt, Germany), Sodium hydroxide. n-hexane.

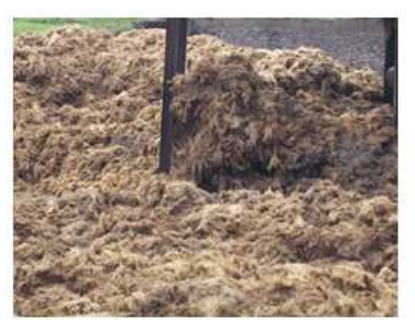

(a)

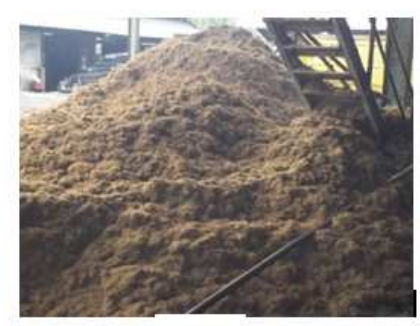

(b)
Figure 1. Bpfc (a) and Cfc (b) (Doc. PT. Palm Oil Plantation BioNusantara Indoneisa, Bengkulu).

\subsection{Characterizations}

The FT-IR spectra of bunch press fibre cellulose and cyclone fibre cellulose were characterized using a FTIR spectrometer (Shimadzu IR PRESTIGE-21). The samples were taken at wave numbers in the range of 400 to 4500 $\mathrm{cm}^{-1}$.

Thermal stabilities of bunch press fibre cellulose and cyclone fibre cellulose were examined by TG analyses with a NETZCH TG 209F3 TGA. Sample weighed $10 \mathrm{mg}$ inserted into the crucible. Analysis were performed with a scanning program temperature from $0^{\circ} \mathrm{C}$ to $200^{\circ} \mathrm{C}$ with a heating

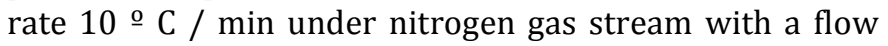
rate of $20 \mathrm{~mL} / \mathrm{min}$.

Analysis of the glass transition using Mettler Toledo DSC 821 type. Sample weighed about 4-5 mg and put in a crucible $40 \mathrm{~mL}$. Analyses were performed with temperature program from $-10{ }^{\circ} \mathrm{C}$ to $250{ }^{\circ} \mathrm{C}$. Heating rate was $10 \stackrel{\circ}{\circ} / \min$. Used as a purge gas with a nitrogen gas flow rate of $50 \mathrm{ml} / \mathrm{min}$.

The X-ray powder diffraction (XRD) analysis was performed using an X-ray diffractometer (Rigaku D-MAX 2200 , Japan) with $\mathrm{Cu} \mathrm{K \alpha}(\lambda=1.5406 \mathrm{~A})$ radiation over the range $2 \theta$ between $0^{\circ}$ and $80^{\circ}$.

The average degrees of polymerization (DP) of the cellulose were determined by British Standard Methods for determination of limiting viscosity number of cellulose in dilute solutions, part 1, cupri-ethylenediamine (CED) method (BS 6306: part 1: 1982) [8-10].

\section{RESULTS AND DISCUSSION}

3.1. The average degree of polymerization (DP)

The average degree of polymerization obtained through semi-empirical method by measuring the viscosity of bunch press fibre cellulose and cyclone fibre cellulose. The bunch press fibre cellulose and cyclone fibre cellulose obtained from the pulping process using a solution of $18 \%$ sodium hydroxide with heating temperature of $135{ }^{\circ} \mathrm{C}$ for 4 hours. The average degree of polymerization of the obtained results as follows:

a. The average degree of polymerization Bpfc.

Curves obtained from the straight-line equation Figure 2:

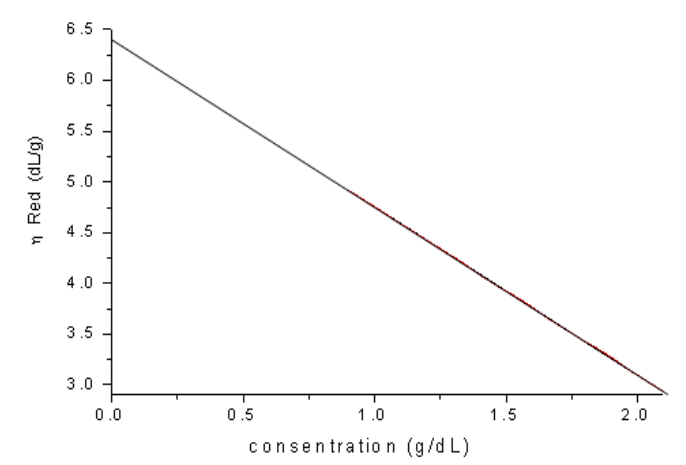

Figure 2. Curve concentration $(\mathrm{g} / \mathrm{dL})$ of $\eta$ reduced $(\mathrm{dL} / \mathrm{g})$ Bpfc.

$$
\mathrm{Y}=-1.65 \mathrm{x}+6,4
$$

Intrinsic viscosity was obtained $\eta_{\text {ins }}=6.4 \mathrm{dL} / \mathrm{g}=640$ $\mathrm{mL} / \mathrm{g}$

By using the following equation below [8]:

$$
\mathrm{Dp}^{0.9}=1.6 \times \eta_{\text {ins }}
$$

Degree of polymerization of Bpfc have been obtained 2195.

b. The average degree of polymerization Cfc. 
Curves obtained from the straight-line equation Figure 3:

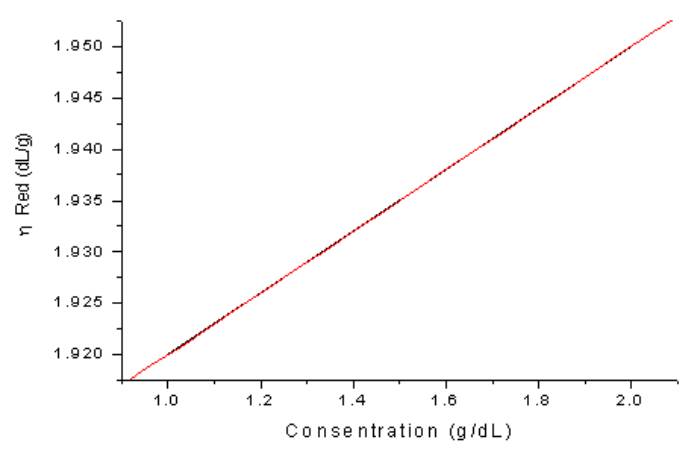

Figure 3. Curve concentration $(\mathrm{g} / \mathrm{dL})$ of $\eta$ reduced $(\mathrm{dL} / \mathrm{g}) \mathrm{cfc}$.

$$
\mathrm{Y}=0.03 \mathrm{x}+1.89
$$

Intrinsic viscosity was obtained $\eta_{\text {ins }}=1.89 \mathrm{dL} / \mathrm{g}=189$ $\mathrm{mL} / \mathrm{g}$

By using the following equation below:

$$
\mathrm{Dp}^{0.9}=1.6 \times \eta_{\text {ins }}
$$

Degree of polymerization of Cfc have been obtained 567.

Degree of polymerization is defined as the number of monomer repeat unit that forms a polymer. Required to estimate the degree of polymerization of relative molecular mass average of a polymer.

The average degree of polymerization of Bpfc greater thanCfc. This is a logic consequence of the metabolism of plant palm oil on each different section. The average degree of polymerization Cfc was smaller because it is possible cyclone fibre cellulose derived from the shells of palm oil which is part of metabolism is the main palm oil. At bunch press fibre obtained considerable degree of polymerization, because at this point there is no primary metabolism such as the palm oil shell. The average degree of polymerization of the bunch press fibre cellulose, when compared with previous studies reporting the degree of polymerization of the bacterial cellulose material nearing beet molasses [1]. Other studies have reported on the degree of polymerization of sugarcane bagasse [8]. Table 1 showed the comparison the average degree of polymerization of the results of this study and previous studies.

Table 1. Comparison of the average degree of polymerization (DP) of several cellulose.

\begin{tabular}{cll}
\hline No & \multicolumn{1}{c}{ materials } & Dp \\
\hline 1 & Cyclone fibre cellulose & 567 \\
2 & Bunch press fibre cellulose & 2195 \\
3 & Bacterial Cellulose from beet & $2695^{*}$ \\
& molasse & $2197^{* * *}$ \\
4 & Cellulose sugarcane bagasse & $2117^{* * *}$ \\
5 & Cotton fibres Egypt Giza, A & $365^{* * *}$ \\
6 & Cotton fibres Egypt Giza, B & \\
\hline & $*[1], * *[8], * * *[11]$.
\end{tabular}

\subsection{Solubility of cellulose}

Solubility of cellulose needed to test the chemical durability, as well as useful for studying the nature or character of the physicochemical cellulose. Several research reports previously known that cellulose is poorly soluble in the solvent sodium hydroxide, methanol and acetone [12]. The solution is highly alkaline since it was prepared directly from copper (II) hydroxide. Cellulose forms a coordinated complex with metal ion where glycol group of a 1,4 anhydroglucose unit of a cellulose molecule chelates to occupy two of the coordination sites of the copper (II) ion displacing a mole of ethylenediamine [1314]. The complex formation between cellulose glycol and copper (II) by examined a series of partly methylated celluloses with different glycol content had studied. It had been evident that, there were direct correspondence between bound copper and the number of glycol groups as measured by optical rotation [14].

From literature have known that the views of solubility, cellulose consists of:

1. $\alpha$-cellulose, which insoluble in $17.5 \% \mathrm{NaOH}$

2. $\beta$-Cellulose, which soluble if the sludge filtrate after determination of $\alpha$-cellulose neutralized by $8.3 \% \mathrm{NaOH}$.

3. $\gamma$-Cellulose, which is part of the remains dissolved after deposition of $\beta$-cellulose.

Generally, solubility of cellulose depends on its molecular weight, crystalinity, polymorph. The molecular weight is an important factor for physical and mechanical properties cellulose. Higher molecular weight are advantageous to obtain mechanical properties of cellulosic materials. However, there are few reports on solubility difference between different molecular weight of cellulose [15].

In this study, the concentration of $\mathrm{NaOH}$ used was $18 \%$ when pretreatment, cellulose insoluble. This means that cellulose was obtained as $\alpha$-cellulose type. From observational studies $\beta$-Cellulose and $\gamma$-cellulose showed a partial dissolution on the concentration of $18 \% \mathrm{NaOH}$. At this concentration, other minor components; lignin, hemicellulose, xylan and others allegedly involved degradable and lost through leaching. Results of previous reports that cellulose can be dissolved in the solvent cupriethylenediamine (CED) [8-10]. In this study, bunch press fibre cellulose and cyclone fibre cellulose soluble in cupriethylenediamine. The Solubility of cellulose obtained in this study is completely presented in Table 2.

\begin{tabular}{lllll}
\multicolumn{5}{c}{ Table 2. Solubility of cellulose } \\
\hline \multirow{3}{*}{ No } & $\begin{array}{c}\text { Time/shaking } \\
\text { (Hours) }\end{array}$ & \begin{tabular}{c} 
Consentration \\
\cline { 4 - 5 }
\end{tabular} & CED $(\mathrm{M})$ & \multicolumn{2}{c}{ solubility } \\
\cline { 4 - 5 } & 36 & 0.75 & Bpfc & Cfc \\
2 & 36 & 2.00 & Insoluble & Insoluble \\
3 & 36 & 2,50 & Little partial & Little partial \\
& & & soluble & soluble \\
4 & 36 & 5 & Soluble & Soluble \\
\hline
\end{tabular}

Table 2 showed the results of the solubility of cellulose, that at lower concentrations to measures of cellulose is insoluble. The hydrogen bonds formed in the cellulose molecule is so large, at low concentrations equivalent mole between solvent and cellulose are not balanced. So it is necessary to dissolve cellulose with solvent mol equivalent amount to much more. The process 
of dissolving, the interaction between cellulose and solvent CED through hydrogen bonding. In addition to cellulose can also occur on the interactions among the fibres or the fibre to the other through hydrogen bonding.

\subsection{FT-IR}

The functional groups of the polymer, such as Bpcf and Cfc were determined using the FT-IR. Analysis have taken to ensure that the cluster functions and spectra obtained show that the resulting product is cellulose. Figure 4 Shows spectrum of bunch press fibre cellulose and cyclone fibre cellulose.

Characterization of functional groups of both types of cellulose fibres were showed peaks typical FTIR spectrum at $3350 \mathrm{~cm}^{-1}$ region $-\mathrm{OH}$ stretching vibration, $2944 \mathrm{~cm}^{-1} \mathrm{C}$ $\mathrm{H}$ stretching vibrations, $1647.1 \mathrm{~cm}^{-1}-\mathrm{OH}$ bending vibration, the area around $1379-1431 \mathrm{~cm}^{-1}$ corresponding $\mathrm{C}-\mathrm{H}$ bending vibrations of methylene and methyl, the area $1250 \mathrm{~cm}^{-1}$ attributed $\mathrm{OH}$ bending vibration, around 962$1150 \mathrm{~cm}^{-1} \mathrm{CO}$ stretching region for $\mathrm{C}-\mathrm{OC}$ and $\mathrm{C}-\mathrm{OH}$ cellulose glycoside bond that states and regions around $420-871 \mathrm{~cm}^{-1}$ ring vibration. The results have shown that the spectrum obtained is fibre cellulose, this spectrum has similarities with the FT-IR spectrum have been reported of the material palm kernel [16].

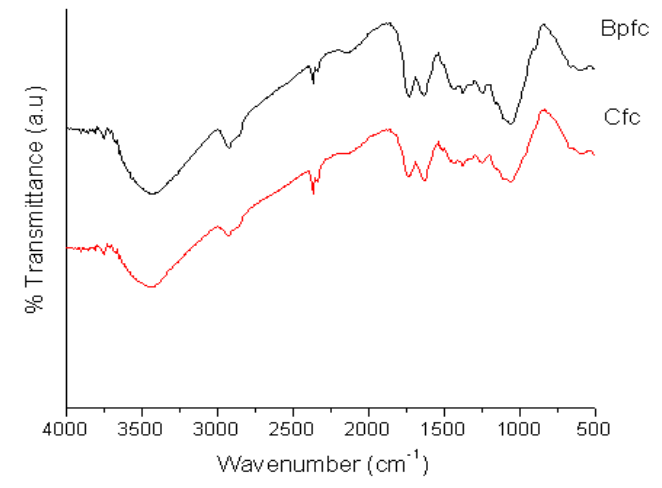

Figure 4. FT-IR spectrum of Bpfc and Cfc.

\subsection{X-ray diffraction analysis}

Crystallinity of Bpfc and Cfc have affect the nature and use, the degree of crystallinity of bunch press fibre cellulose and fibre cyclone have been determined by X-ray diffraction. Figure 5 shows Diffractogram of Bpfc and Cfc. Compared with sugarcane bagasse cellulose previous study, the crystallinity of Bpfc and Cfc have similarities pattern with sugarcane bagasse cellulose [8]. Diffractogram pattern of Bpfc and Cfc at $2 \theta$ between $10^{\circ}$ to $20^{\circ}$ produces a slightly flared shape patterns compared between $20^{\circ}$ and $25^{\circ}$. At the height of $35^{\circ}$ showed a lower crystalline part of the two types of cellulose, as a whole it shows that the cellulose of this study is a semi-crystalline polymer. X-ray diffractogram of cyclone fibre cellulose produces sharp shoulder less than bunch press fibre cellulose.

Diffractogram peak intensity of sugarcane bagasse cellulose is somewhat higher and sharper area between $20^{\circ}$ and $25^{\circ}$, when compared to bunch press fibre cellulose and cyclone fibre cellulose. From diffractogram, the intensity of the shoulder in the area between $0^{\circ}$ and $20^{\circ}$ for sugarcane bagasse cellulose lower or deeper than bunch press fibre cellulose and cyclone fibre cellulose [8]. Previous study has reported that the XRD pattern from bacterial cellulose is shown weak broad peaks $23.5^{\circ}$ at $2 \theta$ [17]. X-ray diffractgram of cellulose whatmann also shows pattern peak between $10^{\circ}$ to $25^{\circ}$ at $2 \theta$ [15].

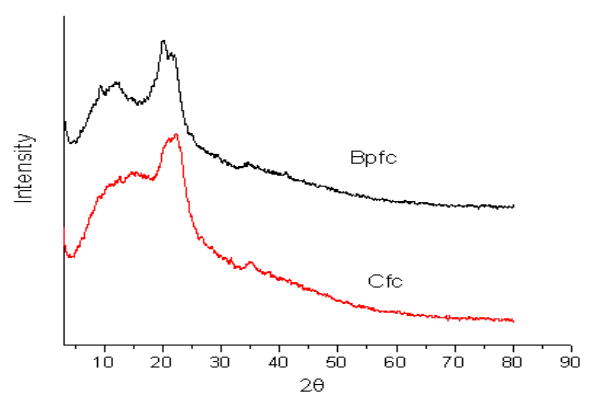

Figure 5. Diffractogram of Bpfc and Cfc.

\subsection{Thermal analysis}

Thermal analysis is a technique commonly used to observe and study the stability of a polymer to heat as well as the dependence of polymer degradation pattern of a polymer. Among the polymers with other polymers have different patterns degradation, it also happens to bunch press fibre cellulose and cyclone fibre cellulose as a natural polymer that is influenced by the nature of the supramolecular cellulose.

Figure 6 shows that Bpfc and Cfc fairly high stability up to $250{ }^{\circ} \mathrm{C}$. The temperature At $100{ }^{\circ} \mathrm{C}$ shows that the Cfc has demonstrated the occurrence of decomposition with a small weight, this suggests that shows still another component such as water. Nevertheless Cfc remains stable up to $250{ }^{\circ} \mathrm{C}$. Temperatures above $250{ }^{\circ} \mathrm{C}$ both types of cellulose degradation began to show up to $50 \%$, and above $350{ }^{\circ} \mathrm{C}$ cellulose backbone begins to show the termination of the main chain. The Cfc sharp degradation than Bpfc.

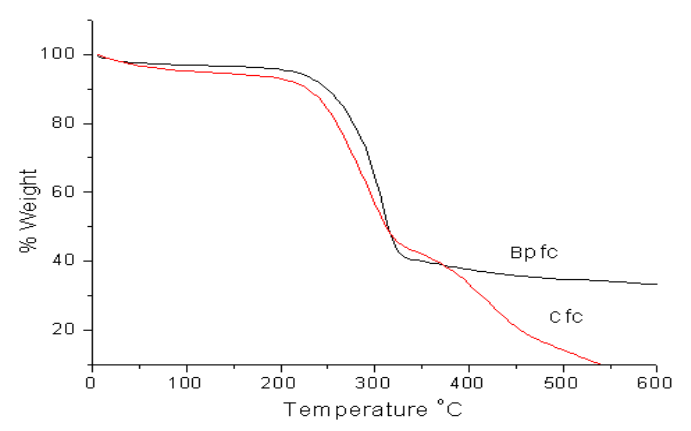

Figure 6. Thermogram of Bpfc and Cfc.

Previous study from the TGA curve of bacterial cellulose showed a typical decomposition curve of pure compound where only one step of decomposition was observed [18]. In the present work, similar with the other research that the purity of the polymer extracted from cellulose [11]. Since the analysis was performed under nitrogen atmosphere, no oxidation occurred. In this inert 
condition, sequence of reactions occurs as cellulose being heated. The first reaction is dehydration of cellulose, an endothermic process known as dehydrocellulose [11,19]. After that, depolymerization reaction took place and yielded levoglucosan (1,6-anhydro-ß-D-glucopyranose) as an essential intermediate. Dehydrocellulose that was produced in the earlier reaction was then going through decomposition and later produce gaseous products (CO, $\mathrm{CO}_{2}$ ) and residual char $[11,19,20]$.

From DSC analysis have found glass transition for bunch press fibre cellulose $102,48^{\circ} \mathrm{C}$ and cyclone fibre cellulose $74,54^{\circ} \mathrm{C}$. This is presumably due to differences in the degree of polymerization of the cyclone fibre cellulose shorter than the bunch press fibre cellulose. Cellulose degradation pattern of this study is similar to previous report [8].

\section{CONCLUSIONS}

In the present work, the average degree of polymerization (DP) of the bunch press fibre cellulose and cyclone fibre cellulose have been obtained 2195 and 567. Solubility analysis of the bunch press fibre cellulose and cyclone cellulose fibre that can be dissolved in a solvent 5 M cupriethylenediamine (CED) each other. From spectrum of FT-IR analysis, showing peaks specific and appropriate to state that the material is cellulose. Xray diffraction patterns explained that the two materials are semi-crystalline and from TGA have shown that cellulose is stable up to temperatures of $250{ }^{\circ} \mathrm{C}$. Temperatures of glass transition (Tg) have been found $102,48^{\circ} \mathrm{C}$ and $74,54^{\circ} \mathrm{C}$ for Bpfc and Cfc respectively.

\section{ACKNOWLEDGMENT}

This work was supported by Research Projects BOPTN 2013 Universitas Bengkulu, Ministry of Education and National Culture of Republic Indonesia.

\section{REFERENCES}

[1] Sherif, M.A.S. Keshk., Taha, M.A. Razek., Kazuhiko, S. (2006). Bacterial cellulose production from beet molasses. African Journal of Biotechnology 5 (17): 1519-1523.

[2] Mansfiel, S.D.. Meder, R. (2003). Cellulose hydrolysis-the role of monocomponent cellulases in crystalline cellulose degradation. Cellulose 10: 159-169.

[3] Kadla, J.F., Gilbert, R.D. (2000). Cellulose structure: A review Cellulose Chem Technol 34:197-216.
[4] Directorate-General Ministry of Agriculture-Republic Indonesia (2006). Documents. Jakarta Indonesia.

[5] Adsul, M.G., Ghule, J.E., Singh, R., Shaikh, H., Bastawde, K.B., Gokhale, D.V., Varma, A.J. (2004). Polysaccharides from bagasse: Applications in celluloase and xylanase production. Carbohydr Polym 57: 67-72.

[6] Buchala, A.J., Fraser, C.G., Wilkie, K.B. (1972). Extraction of hemicellulose from oat tissues during the process of delignification. Phytochemistry 11: 1249-1254.

[7] Hoije, A., Grondahl, M., Tommeraas, K., Gatenholm, P. (2005). Isolation and characterization of physicochemical and material properties of arabinoxylans from barley husks. Carbohydr Polym 61: 266-275.

[8] Chuan, F.L., Jun, L.R., Feng, X., Run, C.S., Jina, J.L., Jin, X.S. (2006). Isolation and characterization of selulosa obtained from ultrasonic irradiated sugarcane bagasse. J Agric Food Chem 54: 5742-5748.

[9] Štefan, Š., Katarína, P., Svetozár, K., Sona, K., Michal, J., Katarína, V., Milan, V. (2012).Change in the capability of cellulose fibres to retain water during thermally accelerated ageing of paper. Cellulose Chem Technol 46: 631-63.

[10] Brinchi, L., Cotana, F., Fortunati, E., Kenny. J.M. (2013). Production of nanocrystalline cellulose from lignocellulosic biomass: technology and applications. Carbohydrate Polymers 94: 154-169.

[11] Lidija, F., Karin, S.K., Majda, S.S.,Volker, R., Tatjana, K. (2002). Quantitative determination of carboxyl groups in selulosa by complexometric titration. Univ of Maribor Inst of Textile Chem Lab. for Characterization and Processing of Polymers, Smetanova 17. 2000 Maribor, Slowenia

[12] Nadia, H., Mohd, C.I.A., Ishak, A. (2012). Physicochemical properties and characterization of nata de coco from local food industries as a source of cellulose. Sains Malaysiana 41(2) : 205-211.

[13] Johnson, D.C. (1985). Solvents for cellulose. In Nevell TP, zeronian S $\mathrm{H}$ (ed.) Cellulose Chemistry and its Applications, Ellis Horwood Limited, New york.

[14] Reeves, R. (1951). Cuprammonium-glycoside complexes. In Hudson CS and Cantor S M. (editor) Advances in Carbohydrate Chemistry Academic Press Inc. New York.

[15] Kazuyuki, H., Emiko, A., Takashi, Y., John, A.C. (2004). New solvents for cellulose II ethylenediamine/thiocyanate salt system. Polymer Journal 36 (2): 123-130.

[16] Bono, A, Ying, P.H., Yan, F.Y., Muei, C.L., Sarbatly, R., Krishnaiah, D. (2009). Synthesis and characterization of carboxymethyl cellulose from palm kernal cake. Advances in Natural and Applied Sciences 3(1): 5-11.

[17] Satish, V., Drillon, M., Derory, A. (2010). Magnetically responsive bacterial selulosa: Synthesis and magnetic studies. Journal of applied physics 108: 0539051-0539057.

[18] Bottom, R. (2008). Thermogravimetric Analysis. In Gabbott, P (editor) Principles and Applications of Thermal Analysis pp 87-118. Blackwell Publishing UK.

[19] Kilzer, F.J., Broido, A. (1965). Speculations on the nature of cellulose pyrolysis. Pyrodynamics 2: 151-163.

[20] Arseneau, F.D. (1971). Competitive Reaction in the Thermal Decomposition of Cellulose. Canadian Journal of Chemistry 49: 632638. 